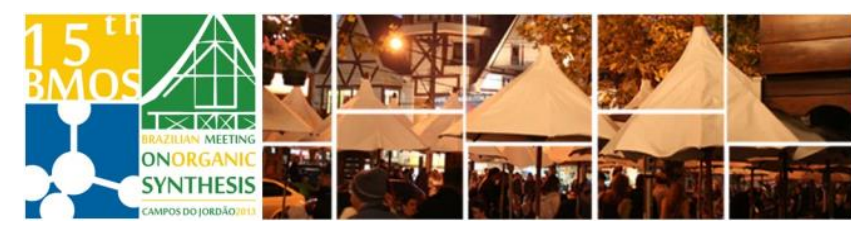

\title{
General substrates for stereoselective synthesis: utilization of D- and L-arabinose
}

\section{Fábio da Paixão Soares, ${ }^{1}$ Maria Joselice e Silva ${ }^{2}$ and Bogdan Doboszewski ${ }^{1 *}$}

${ }^{1}$ Departamento de Química and Departamento de Ciências Moleculares, Universidade Federal Rural de Pernambuco, 52171-900 Recife, PE; ${ }^{2}$ Departamento de Farmácia, Universidade Federal do Rio Grande do Norte, 59010-180 Natal, RN, Brasil

\section{*bdoboszewski@hotmail.com}

Keywords: arabinose; stereoselective synthesis; deoxygenation

\section{INTRODUCTION}

Carbohydrates are convenient chiral substrates during the stereoselective synthesis since their absolute configurations are known just like the methodologies of their functionalization. Both D- and L-arabinose are particularly interesting as the starting compounds since the same synthetic conditions can be used to obtain the enantiomeric products. Reported here are four procedures of deoxygenation at the position C3 of 5- $t$ butyldiphenylsilyl-1,2-O-isopropylidene-D- and -Larabinofuranose 1 and 7 , respectively, to obtain 3deoxy-1,2-O-isopropylidene-D- and Lthreopentofuranose $\mathbf{3}$ and $\mathbf{9}$, respectively, as the general substrates for further applications. ${ }^{1}$

\section{RESULTS AND DISCUSSION}

Apparently simple Barton deoxygenation of $\mathbf{1}$ proceeded with a low yield (Scheme 1). The product 2 was desilylated to obtain the first general substrate 3 whose tosylate 4 crystalized in ${ }^{4} \mathrm{E}$ and ${ }^{4} \mathrm{~T}_{3}$ conformations of the pentofuranosyl ring. ${ }^{2}$

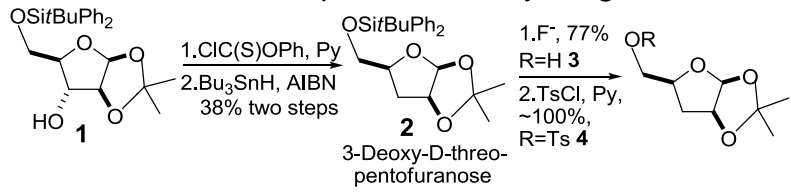

Scheme 1. Deoxygenation of 1: first approach, via a Barton reaction.

A modified Wolff-Kishner reaction was tried next in an attempt to improve the yield of $\mathbf{2}$, without much success, Scheme 2.

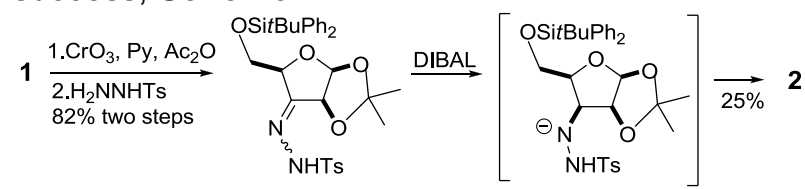

Scheme 2. Deoxygenation of 1: second approach, via a modified Wolff-Kishner reaction.

Low yield obtained prompted us to use another version of the Barton reaction as shown in the Scheme 3 which furnished the compound 3 again in low yield. The intermediate D-lyxo compound $\mathbf{5}$ was obtained with a total stereoselectivity.

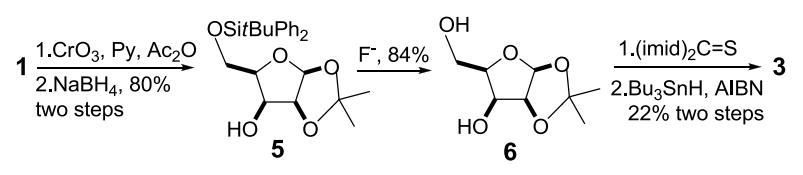

Scheme 3. Deoxygenation of 1: third approach using a Barton type reaction via 1,2-O-isopropylidene-Dlyxofuranose 6 and its thiocarbonate.

The best yielding method to get 2 and its Lenantiomer $\mathbf{8}$ is shown in the Scheme 4.

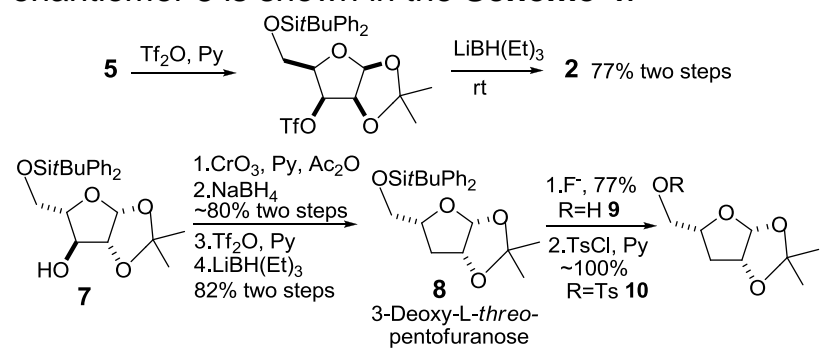

Scheme 4. Deoxygenation of 1 and its L-enantiomer 7: fourth approach: "substitutive deoxygenation" via the lyxo triflates and $\mathrm{LiBH}(\mathrm{Et})_{3}\left(\right.$ Superhydride $\left.{ }^{\circledR}\right)$.

Both enantiomers 3 and $\mathbf{9}$ are referred to as the general substrates. Their possible application in stereoselective synthesis may include obtention of chiral hydroxyaldehydes, alcohols or diols, among others, as shown below for the D enantiomer 3 .

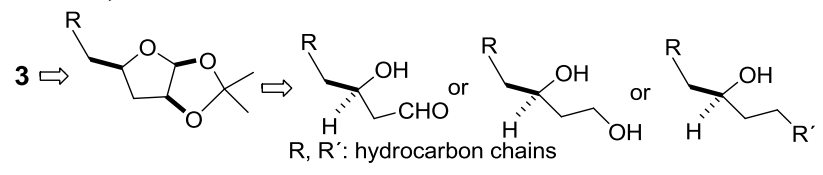

Efficient deoxygenation at the C3 position of D- and L-arabinofuranose was devised which furnished the derivatives 3, 4, 9 and 10 for further manipulations.

\section{ACKNOWLEDGEMENTS}

Post-graduation Program in Chemistry of the UFRPE is acknowledged for financial support.

\section{REFERENCES}

1 Soares, F.P.; Silva, M.J. e; Doboszewski, B. Carbohydr.Res. 2013, accepted, and references therein.

${ }^{2}$ Doboszewski, B.; Silva, M.J. e; Nazarenko, A.; Nemykin, V.N. Acta Cryst. E 2012, E68, 1109.

\footnotetext{
$15^{\text {th }}$ Brazilian Meeting on Organic Synthesis $-15^{\text {th }}$ BMOS - November 10-13, 2013 - Campos do Jordão, Brazil
} 